\title{
Different Cultures and Social Patterns Matter in English and Chinese Greetings
}

\author{
Linqi Liu \\ Beijing University of Posts and Telecommunications, China
}

\begin{abstract}
Greetings can be found in all languages. They are linguistic routines that form part of the repertoire of politeness and serve as means for opening conversations appropriately, establishing, maintaining and negotiating social relationships. While such routines have been studied in disciplines such as sociology, anthropology, sociolinguistics and discourse analysis, there has been not enough quantitative and qualitative study on the use of greetings in and across different languages, cultures and social patterns. Consequently, the present study aims to undertake such a research in English and Chinese. The present study indicates that great differences can be found in the contents, the frequency, degree of politeness, distribution of greeting and its use in the form of address terms between English and Chinese. Linguistic routines of greeting, far from being relatively meaningless and mechanical social behavior, can be understood as extremely important strategies for negotiation, control of social identity and social relationship between participants in conversation. Problems in cross-cultural communication and in different social patterns are easily seen in the use of greeting between English and Chinese speakers.
\end{abstract}

\section{Introduction}

Greeting can be described as the exchange of expressions, pleasantries or good wishes between two people interacting for the purpose of fulfilling social obligations, or for the establishment of interpersonal relationships. It takes place at the opening of an interaction or as a marker of its closing. It can be regarded as a necessary opening to every new encounter.

Greetings are also linguistic routines that form part of the repertoire of politeness [1]. It has been referred to as an "interactional ritual" [2], "an interactional routine" [1], or a conventionalized episode of interaction in the opening phase of a conversation [3]. It is informed by rules of conduct, and is an inevitable part of everyday conversation.

With socio-cultural significance, its realization is usually language specific. The present study is based on the combination of quantitative and qualitative, theoretical and practical approaches. On-line research was used in order to prove its validity for linguistic studies. The implications of greetings in both languages and their underlying social pattern factors, cultural factors and philosophical sources factors are also explored.

\section{Literature Review}

Generally speaking, greetings represent an acknowledgement of the relationship between two individuals. Also, the act sets up the possibility for further relationships. The kind and number of several parameters involved in greeting exchanges as a speech event, according to academics across the three disciplines, linguistics, sociology, and anthropology, are expectedly mixed. These three disciplines view greetings across a spectrum of proximity from micro to macro. Linguists represent the micro view, focusing on linguistic behavior. Sociologists take a step back by looking more at social interaction. Lastly, anthropologists have taken a larger view, interpreting the linguistic behavior of greetings coupled with interaction as representing culture.

Schegloff see greetings as a speech event composed of two parts side by side, serial, and sequential[4]. Erving Goffman prefers to characterize greeting exchanges as "access rituals" consisting of two types, passing greetings and engaging greetings [2]. Laver makes a further study of the rationale for the existence of routine elements such as greetings in the linguistic patterns of conversation [1]. Brown and Levinson put forward their model of politeness. Greetings as conversational routines are part of the linguistic repertoire of politeness [5].

Compared with the study abroad, research on greetings in China is carried out much later. Most works are focused on vocatives. The past three decades has witnessed the progress of Chinese politeness research. Several scholars have also made some modifications of the Western politeness theories. For example, Gu Yueguo [6] has made a contrastive analysis of politeness phenomenon between Chinese and English and has pointed out the cultural difference in politeness phenomenon. Jia Yuxin [7] made a comparison of interpersonal relationship and intercultural communication between the East and the West. As for greetings, Qian Housheng [8] carried out a contrastive study of linguistic routines and politeness on greetings and partings in English and Chinese. 


\section{Research Methodology}

\subsection{Study Objective and Research Questions}

The main purpose of this study is to examine what strategies are employed in English and Chinese greetings and whether such strategies are influenced by English and Chinese cultures and social patterns. To achieve the objectives, researcher will seek answers to the following questions: (1) Whether English and Chinese greetings have significant differences? (2)What are the differences in the frequency, degree of politeness and distribution of greetings? What are the differences in the use of address terms as greetings in English and Chinese? (3) What factors cause the differences in the use of greetings in English and Chinese?

\subsection{Design of the Study}

The survey was carried out from 80 native English speakers who study or work in the United States and in the UK, and 100 Chinese speakers who study or work in China through the Internet. The subjects were chosen randomly. The valid questionnaires are altogether 94 from 47 English speakers and 47 Chinese speakers.

There are in total two parts, fifteen questions in the questionnaires with English version and Chinese version. The first part includes six major questions in investigating the frequency of use of different linguistic routines, the perception of degree of politeness, the distribution of routine expressions among different types of addressees. And some questions are put forward in questionnaires to elicit regional varieties of greetings as such expressions are very restricted in use. The second part is selfreport about the subjects, including nine questions related to age, sex, nationality, hometown, living time, speaker-type, regional varieties of English (if any), educational level and occupation. After checking the answer sheets and excluding the invalid ones, the researcher will analyze the E-groups.

\subsection{Data Collection and Data Coding}

Results of the empirical study will be presented relating to the questions and hypothesis of the study from both quantitative and qualitative perspectives. The 23.0 version of SPSS was applied to do the Independent-sample T-test, Descriptive Statistics and Frequencies so that it provides the scientific results to give the evidence. In addition, individual feedbacks and personal communication with the subjects were also used in order to find out other factors affecting greetings.

\section{Findings and Discussion}

In terms of the statistical technique, researcher will interpret differences in content, frequency of use, degree of politeness, address terms in the distribution of specified English and Chinese greetings and other related aspects.

\subsection{Differences in contents}

Differences in English and Chinese greetings are remarkable. "Good morning/afternoon/evening" are common greeting expressions in English, whereas "Have you eaten" "Where are you going?" are common greetings in Chinese.

We can divide greetings into five kinds of greetings.

Table 1. Categories of Greeting by the Researcher

\begin{tabular}{|l|l|l|}
\hline No & English & Chinese \\
\hline 1 & All-time greetings & 随时问候语 \\
\hline 2 & Real-time greetings & 实时问候语 \\
\hline 3 & Formal greetings & 正式问候语 \\
\hline 4 & Weather greetings & 天气问候语 \\
\hline 5 & Inquiry greetings & 询问问候语 \\
\hline & Others & 其他 \\
\hline
\end{tabular}

In general, Chinese greeting is more situational and less dependent on formulaic greetings. They tend to take their subject matter from the circumstances of a particular greeting. They can therefore be more "personal" than the set phrases or formulae that are used in English. It is argued that the use of terms for Chinese greeting depends more on acknowledgement of the setting of a verbal exchange than that in western languages. The differences in content on English and Chinese greetings may suggest different choice of politeness strategies by the two people.

\subsection{Differences in Frequency of Use}

The differences in the use of greetings between English and Chinese were first tested through a number of experiments on the frequency of use of specified common English expressions, followed by those translated literally from Chinese and vice versa. The English and Chinese informants were asked to indicate to what extent each of them used those expressions to greet to others by marking in the blank before each expression a frequency score of 1 to 5 (from very frequent to never), 1 for very frequent, 2 for frequent, 3 for sometimes, 4 for rarely and 5 for never. According to table 1, the greetings will be explored in details.

(1)All-time greetings: Hello! / Hi! Etc.

(2)Real-time greetings: Good morning! / Good afternoon! / Good evening! /Good day! 
(3)Formal greetings: How do you do? / How are you? / How is your work? Etc.

(4)Weather greetings: It is a fine day! / It is a fine day, isn't it? Etc.

(5)Inquiry greetings: Have you eaten? / Where are you going? / What are you busy with? Etc.

The related test is the "Independent-Samples $T$ Test." The lower the score is, the more frequently it is used and vice versa. The scores suggest that both English and Chinese frequently use "Hello" and "Hi" in their daily life for greeting. Expressions equivalent in literal meaning to the English "Good morning", "Good afternoon", "Good evening" are less frequently used by Chinese informants. While English informants ask people about their health more often than about their work in greeting, Chinese informants seem to do the opposite. English informants use greeting expressions with tag questions less frequently than those without tag questions, so do the Chinese informants. Questions such as "Have you eaten?", "Where are you going?" and "What are you busy with?" are much more frequently used by Chinese informants than English informants.

\subsection{Differences in Degree of Politeness}

Greetings are linguistic routines concerned with politeness in social interaction. In Brown and Levinson's [5] model of politeness, five strategies related to the maintenance of "face" are identified. We would argue that this typology may need to be substantiated by the notion of degree of politeness so as to avoid criticisms of overgeneralization.

In our experiments on the informants' perception of degree of politeness in English and Chinese greetings, we adopted Clark \& Schunk's [9] sevenpoint scale. We put several sets of English and Chinese expressions in random order and asked our informants to evaluate the degree of politeness of such expressions by marking a score of 1 to 7 (from very polite to very impolite) for each expression. (1 for very polite, 2 for fairly polite, 3 for somewhat polite, 4 for neither polite nor impolite, 5 for somewhat impolite, 6 for fairly impolite, or 7 for very impolite)

Table 2. Politeness Scores of Specified English Greeting Expressions

\begin{tabular}{|l|l|}
\hline English Expressions & Scores \\
\hline Good morning, Mr. Smith! & 1.45 \\
\hline Good morning! & 2.15 \\
\hline Morning, Mr. Smith! & 2.20 \\
\hline Morning! & 2.45 \\
\hline Hello! Mr. Smith! & 2.84 \\
\hline Hello! & 3.10 \\
\hline Hi! Mr. Smith! & 3.75 \\
\hline Hi! & 3.85 \\
\hline Mr. Smith! & 5.12 \\
\hline
\end{tabular}

According to "Descriptive statistics" of SPSS 23.0, let us examine the mean scores of perceived degree of politeness in specified English and Chinese greeting expressions indicated by the informants in Table 2 and Table 3.

Table 3. Politeness Scores of Specified Chinese Greeting Expressions

\begin{tabular}{|l|l|}
\hline Chinese Expressions & Scores \\
\hline 李先生, 您早! & 1.25 \\
\hline 李先生, 早啊! & 2.54 \\
\hline 李先生, 早! & 2.82 \\
\hline 您早! & 2.95 \\
\hline 早啊! & 3.43 \\
\hline 早! & 3.65 \\
\hline 嘿, 李先生! & 3.70 \\
\hline 李先生! & 4.83 \\
\hline 嘿! & 4.98 \\
\hline
\end{tabular}

The scores in the above tables indicate that English and Chinese speakers have an intuitive sense of the degree of politeness in greetings. The lower the score is, the more polite it is. Based upon these two tables, the following general statements can be made: First, in both English and Chinese, greeting expressions with terms of address are perceived to be more polite than those without. Second, terms of address used as independent greetings are perceived to be more polite in Chinese than in English.

\subsection{Differences in Address Terms as Greeting}

As shown in Section 4.3, the use of terms of address as politeness intensifiers can be evaluated through a comparison between the scores of greetings with and without address terms in English and Chinese.

Chinese has evolved a much more complex system of address terms in kinship than English [10]. For Chinese, kinship means a tie based first on birth and second on marriage. We can easily see that relatives outside the parents-children configuration have much more significance for Chinese than for English. Another difference in the terms of address between English and Chinese is how to address person of various social status and professions. Chinese has evolved a set of terms of direct address for them according to their specific social status and professions.

The questionnaires were undertaken in the form of judgmental tests. English and Chinese informants were asked to indicate what terms of address they were likely to use for each specified type of addressees in Table 4. 
Table 4. Percentage of English Informants Using Specified Terms of Address to Different Types of Addressees

\begin{tabular}{|l|l|l|l|l|l|l|l|}
\hline Terms of Address & PAR & S/D & W/H & FRI & SUP & INF & STR \\
\hline First name & 25 & 45 & 73 & 100 & 56 & 62 & 0 \\
\hline Last name & 0 & 0 & 0 & 0 & 0 & 14 & 9 \\
\hline Full name & 0 & 0 & 0 & 0 & 0 & 0 & 0 \\
\hline Title + first name & 0 & 0 & 0 & 0 & 0 & 0 & 0 \\
\hline Title + last name & 0 & 0 & 0 & 0 & 70 & 35 & 41 \\
\hline Title + full name & 0 & 0 & 0 & 0 & 0 & 0 & 0 \\
\hline Professional title & 8 & 0 & 0 & 0 & 36 & 0 & 0 \\
\hline Sir/Madam/Miss & 8 & 0 & 0 & 0 & 9 & 22 & 31 \\
\hline Dear, darling $\ldots$ & 25 & 0 & 38 & 0 & 0 & 0 & 0 \\
\hline
\end{tabular}

\author{
Note: $P A R=$ parents \\ $\mathrm{S} / \mathrm{D}=$ sons/daughters \\ $\mathrm{W} / \mathrm{H}=$ wife/husband \\ $\mathrm{FRI}=$ friends \\ $\mathrm{SUP}=$ superiors \\ $\mathrm{INF}=$ inferiors \\ $\mathrm{STR}=$ strangers
}

Table 5. Percentage of Chinese Informants Using Specified Terms of Address to Different Types of

Addressees

\begin{tabular}{|l|l|l|l|l|l|l|l|}
\hline Terms of Address & PAR & S/D & W/H & FRI & SUP & INF & STR \\
\hline First name & 0 & 30 & 65 & 68 & 0 & 45 & 6 \\
\hline Last name & 2 & 0 & 9 & 65 & 18 & 31 & 25 \\
\hline Full name & 0 & 35 & 9 & 27 & 13 & 47 & 71 \\
\hline Title + first name & 0 & 0 & 0 & 0 & 15 & 29 & 17 \\
\hline Title + last name & 0 & 0 & 0 & 0 & 85 & 27 & 43 \\
\hline Title + full name & 0 & 0 & 0 & 0 & 27 & 20 & 36 \\
\hline Professional title & 15 & 0 & 0 & 0 & 55 & 9 & 25 \\
\hline Sir/Madam/Miss & 0 & 0 & 0 & 13 & 13 & 7 & 43 \\
\hline Dear, darling $\cdots$ & 10 & 15 & 70 & 11 & 0 & 0 & 0 \\
\hline
\end{tabular}

Table 4 and Table 5 show that first name is used more widely in English than in Chinese. It is used to address parents and superiors in English but not in Chinese. The percentage of the use of first names to children, wife or husband, and inferiors is also higher in English than in Chinese. However, while last name and full name are almost not used by English speakers as direct terms of address, they are widely used in Chinese. Title plus first name or full name is not normally used in English conversations but they are used in Chinese to superiors, inferiors and strangers. Professional title is used more widely and more frequently in Chinese than in English.

\section{Main Factors Causing the Differences}

Due to the different socio-cultural norms and values, the connotations of politeness, its manifestations and judging standards vary crossculturally. It seems reasonable to assume that the concept of politeness, which represents an abstract social value, is most probably universal in some form or other.

\subsection{Social factors}

Why should greetings involve such a complex system and what is the rationale for the existence of greeting paradigms? The answer may lie in the social reality and the interactant's communicative intention as many linguistics researchers suggest. Politeness strategies are related closely to the interactant's face: they are used when doing FTAs (face-threatening acts) to maintain the interactants' negative face or to enhance their positive face to any degree. We need to consider the social factors that affect the use of greetings in the choice of appropriate strategies.

Social power and social distance are considered two major factors influencing the choice of greeting. Variables determining the selection of a particular greeting form are numerous, including not only the qualitative characteristics of the speakers-age, sex, kinship relation, occupation, wealth, education, family background-but also more general factors: for instance, the content of the conversation, the presence of the third person. The notion of power and distance are used widely in linguistics. Several classic studies have helped the establishment of power and distance as key variables. Spencer-Oatey emphasized one or more of following aspects: (1) Power of control; (2) Social status or rank; (3) Authority or the legitimate right to exert influence; (4) A general notion of equality-inequality [11].

In a society where hierarchy is emphasized, people with a higher occupational status imply more power. The status relationship between people is strongly relevant in selecting appropriate greetings. Distance is another main factor in determining the choice of suitable greetings. A considerable number of other terms are also used: solidarity, closeness, familiarity and relational intimacy.

\subsection{Cultural factors}

Since western culture stresses individual rights, freedom and independence, showing respect to one's liberty, rights and independence is considered polite. Individualism is also deeply rooted in western culture and is highly valued by English people.

English speakers are known to be rather more considerable. They are particularly sensitive about their negative face as well. Questions such as "Where are you going?" or "What are you doing?" which sound impeding may not be proper to most of them, and thus are not accepted as greetings. Politeness in English culture has been closely associated with the norms of social conduct.

To achieve harmony, Chinese people emphasize implicitness, indirectness, ambiguity and selfrestraint. Collectivism remains at the very core of 
Chinese culture. As opposed to "individualism", "collectivism" is a cultural pattern, consisting of closely linked individuals who see themselves as part of their collectives and give priority to group goals over their own personal goals [12]. It is based on a rigid social framework that makes a distinction between in-groups and out-groups.

Privacy is valued in all cultures, but it is more highly valued in the English culture. Members of individualistic cultures tend to engage in environmental control to assert their unique identity and to claim private space than members of collectivistic cultures do. The Chinese attach great importance to mutual care, which is equally important as modesty.

\section{3. Philosophical source factors}

The most important dominant orientationequality and human rights in English countries and the principle of Ren and $\mathrm{Li}$ - the key concept of Confucianism in China actually act as shapers of the patterns of interpersonal relationship, they are also the philosophical sources which affect interactions and communications such as greetings.

What is emphasized in English culture is individualism and as a result equal or horizontal relationship is highly valued. What is advocated is humanitarianism and human rights of each member and thus the slogan: everybody is born equaldemocracy, liberation of the individual is everybody's wish. In this case, the love and benevolence humanitarianism advocates are symmetrical in nature. The relationships are symmetrical in that behavior which is appropriate to one person in each pair is identical with what is appropriate to the other person. This symmetry presupposes role equality rather than differentiation as is the case in China.

\section{Conclusions}

The empirical study focuses on an investigation of greetings that reflects differences in cultures and social patterns in the notion of people between English and Chinese. The study indicates that great differences can be found in the contents, the frequency, degree of politeness, distribution of greeting and its use in the form of address terms between English and Chinese. Greetings are exchanged not just in order to inform, not just in the case to connect people in action, but to convey the social relationship that the speakers assume or try to establish. It is important to raise our cross-cultural awareness and to develop our communicative competence so as to minimize and/or avoid pragmatic failure and enjoy successful communication across different cultures and social patterns.

\section{Acknowledgment}

This study was supported by Beijing University of Posts and Telecommunications Teaching and Research of Postgraduate Education Project (Y2016004)

\section{References}

[1] Laver. J., "Linguistic Routines and Politeness in Greetings and Partings", In Coulmas, F., editor, Conversational Routine, The Hague: Mouton, 1981, pp.289-304.

[2] Goffman, E., Interaction Ritual: Essays on Face to Face Behavior, New Brunswick, N.J.: Aldine Transaction, 2005.

[3] Ferguson, C.A., "Structure and use of politeness formulas", Language in Society, 5(2),1976, pp.129-136.

[4] Schegloff, E. A., "Sequence in Conversational Openings", American Anthropologist, Vol.70, 1968.

[5] Brown, P. \& Levinson S., Politeness: Some Universals in Language Usage. Cambridge: Cambridge University Press, 1987, pp.62-87.

[6] Gu, Yueguo, Politeness phenomenon in modern Chinese, Journal of Pragmatics, 1990, pp.237-257.

[7] Jia, Yuxin, Cross-culture Communication, Shanghai: Shanghai Foreign Language Education Press, 1997.

[8] Qian, Housheng, Greetings and Partings in English and Chinese: A Contrastive Study of Linguistic Routines and Politeness, Shanghai: Shanghai Foreign Language Education Press, 1996.

[9] Clark, H.H. \& Schunk D.H., "Polite Responses to Polite Requests" Cognition, (8), 1980 pp.111-143.

[10] Li, Mian, "The Analysis of the Level of the Ethical Culture in China from the Kinship Terms", Central China Normal University Journal of Postgraduates, (12) 2012, pp.102-105.

[11] Spencer-Oatey, H., "Reconsidering Power and Distance". Journal of Pragmatics (26), 1996, pp.1-24.

[12] Triandis, H. C., Individualism and Collectivism. Boulder, CO: Westview Press, 1995. 